\title{
Effects of plant growth regulators on transient expression of foreign gene in Nicotiana benthamiana L. leaves
}

Ying Li, Min Sun, Xin Wang, Yue-Jing Zhang, Xiao-Wei Da, Ling-Yun Jia, Hai-Long Pang and Han-Qing Feng* (0)

\begin{abstract}
Background: In the last decades, replicating expression vectors based on plant geminivirus have been widely used for enhancing the efficiency of plant transient expression. By using the replicating expression vector derived from bean yellow dwarf virus and green fluorescent protein as a reporter, we investigated the effects of a-naphthalene acetic acid, gibberellins ${ }_{3}$, and 6-benzyladenine, as three common plant growth regulators, on the plant biomass and efficiency of transient expression during the process of transient expression in Nicotiana benthamiana L. leaves.

Results: With the increase of the concentration of a-naphthalene acetic acid, gibberellins ${ }_{3}$, and 6-benzyladenine (from 0.1 to $1.6 \mathrm{mg} / \mathrm{L}$ ), the fresh weight, dry weight, and leaf area of the seedlings increased first and then returned to the levels similar to the controls (without chemical treatment). The treatment with a-naphthalene acetic acid at 0.2 and $0.4 \mathrm{mg} / \mathrm{L}$ can enhance the level of transient expression of green fluorescent protein, which peaked at $0.4 \mathrm{mg} / \mathrm{L}$ a-naphthalene acetic acid and was increased about by $19 \%$, compared to the controls. Gibberellins ${ }_{3}$ at $0.1-0.4 \mathrm{mg} / \mathrm{L}$ can enhance the level of transient expression of green fluorescent protein, which peaked at $0.2 \mathrm{mg} / \mathrm{L}_{\text {gibberellins }} \mathrm{L}_{3}$ and was increased by $25 \%$. However, the application of 6-benzyladenine led to decrease in the level of transient expression of green fluorescent protein.
\end{abstract}

Conclusions: The appropriate plant growth regulators at moderate concentration could be beneficial to the expression of foreign genes from the Agrobacterium-mediated transient expression system in plants. Thus, appropriate plant growth regulators could be considered as exogenous components that are applied for the production of recombinant protein by plant-based transient expression systems.

Keywords: Plant growth regulators, Agrobacterium-mediated transformation, Geminivirus-derived vector, Transient expression

\section{Introduction}

Transient expression technology refers to the technology of introducing the target gene into recipient cells to establish a temporary high-efficiency expression system so that the target gene can be expressed in a relatively short time. The transformed target gene by the transient expression technology is not integrated into the genome,

\footnotetext{
*Correspondence: fenghanq@nwnu.edu.cn

School of Life Sciences, Northwest Normal University, Lanzhou 730070, China
}

thus saving the time of genetic transformation and screening (Chen et al. 2013).

Production of the desired protein via transient expression has obvious advantages, including less time with more protein expression, lower cost, and easy manipulation without any biosafety concerns, compared to develop stable transgenic lines with time-consuming procedures (Xia et al. 2020). And, in recent years, plants have been emerged as an alternative platform for the production of recombinant proteins to meet the worldwide demand for protein-based pharmaceuticals (Chen 2008). Compared to animal, yeast, and bacteria cells, 
the production of recombinant proteins by plant cells is more reliable, scalable, low cost, and safe (Damaj et al. 2020). And, the recombinant proteins that are produced by transient expression in plants can be extracted within 1-2 weeks after transformation (Leuzinger et al. 2013). Especially today, when new pathogens and diseases are prone to sudden outbreaks, the production of medicinal proteins or antibodies in plants by transient expression system is of great significance for social security and disease treatment (Peyret and Lomonossoff 2015).

For the transient expression of foreign gene in plant, the target gene is transferred into plant cells through a process called agroinfiltration. In simply, leaves are infiltrated with the suspension of Agrobacterium tumefaciens carrying the target gene within a binary vector. Infection of Agrobacterium tumefaciens delivers the target gene into the plant cells. After entering into the plant cells, the most of the target gene remains episomal, instead of integrating into the genome, and can have transcriptionally competent during certain time (Leuzinger et al. 2013).

Nicotiana benthamiana, as a wild relative of tobacco, has been considered as model organism to study the plant-based transient expression. The main reasons underlying this is that Nicotiana benthamiana is a popular host for Agrobacterium tumefaciens, and thus, Nicotiana benthamiana is highly amenable to Agrobacterium-mediated transient expression (Reed and Osbourn 2018)

In the last decades, autonomously replicating expression vectors based on plant geminivirus has been widely used in plant transient expression (Hefferon 2014; Rybicki and Martin 2014). Compared with those non-replicating expression vectors, autonomously replicating expression vectors based on plant geminivirus can produce a large number of copies of target genes after transformation, thus largely enhancing the expression level of the desired protein (Abrahamian et al. 2020). For example, the bean yellow dwarf virus (BeYDV) is one of the geminiviruses in the genus Megaviruses. Its genome is circular singlestranded DNA with a size of $2561 \mathrm{bp}$. After infecting the host plant, BeYDV quickly replicates to a high copy number in the host cell nucleus by rolling circle replication (Chen et al. 2011; Zaidi and Mansoor 2017). Based on the above characteristics, the BeYDV-derived expression vectors are constructed, which contain the replicationrelated elements of BeYDV and an expression cassette for a gene of interest (Zhang and Mason 2006; Baltes et al. 2014). Many works have shown that using the BeYDVderived expression vectors in plant transient expression can generate a large number of target gene copies in plant host cells, thus greatly improving the efficiency of plant transient expression (Richter et al. 2016; Hanley-Bowdoin et al. 2013).
Besides the development of new expression vectors, some efforts are also attempted to further improve the efficiency of transient gene expression in plants. These include the optimization of internal or external factors that could affect the efficiency of plant transient expression, such as the concentration of Agrobacterium tumefaciens, temperature, light intensity, and humidity (Maleki et al. 2018; Fujiuchi et al. 2016). Although some internal factors can be easily controlled, it is still difficult to obtain higher protein yield from transient expression in plants by modifying external environmental factors, especially when the plants used for transient expression were grown in the field. Thus, developing some novel methods that can be easily applied is still needed for enhancing the utility of the plant-based transient expression systems.

Plant growth regulators (PGRs) are a kind of chemical substances synthesized artificially, which can regulate the growth and development of plants by exogenous application (Gong et al. 2021). $\alpha$-naphthalene acetic acid (NAA), gibberellins ${ }_{3}\left(\mathrm{GA}_{3}\right)$, and 6-Benzyladenine (6-BA) are commonly used in agriculture for enhancing the production of crops. NAA, which belongs to the synthetic branch of auxins, is a naphthalene derivative widely used to stimulate plant growth, prevent the premature fall of fruits, and increase the yield of crops (Guan et al. 2011). $\mathrm{GA}_{3}$ is a dihydroxylated gibberellin and can promote the growth and development of plants. $\mathrm{GA}_{3}$ has been applied to regulate seed germination, organ elongation, flowering, and fruit maturity by affecting mitotic frequency or cell enlargement (Hedden and Sponsel 2015). 6-BA is a synthetic cytokinin, which can mediate various physiological processes of plants, such as plant stem and root growth, cell proliferation, chloroplast development, and biomass distribution (Werner et al. 2010; Hwang et al. 2012), thus severing as the regulator for promoting plant growth, increasing chlorophyll content, and delaying senescence (To and Kieber 2008). More importantly, these PGRs are lower cost, relatively cheap, and are easy to apply in the field. However, information about the effects of PGRs on the efficiency of plant transient expression is very limited.

Therefore, in this study, by using the BeYDV-derived replicating expression vector and green fluorescent protein (GFP) as a reporter, we investigated the effects of NAA, $\mathrm{GA}_{3}$, and 6-BA, as three common PGRs, on the plant biomass and efficiency of transient expression during the process of transformation in Nicotiana benthamiana L. leaves. We believe that this study would help provide a reference for how to utilize PGRs to improve the yields of recombinant protein from plant transient expression. 


\section{Materials and methods Experimental material Cultivation of plant materials}

Two or three seeds of Nicotiana benthamiana L. were planted into the peat pell in the seedling box and were cultured in a culture room with a temperature of $25{ }^{\circ} \mathrm{C}$, a humidity of $50 \%$, and a day and night period of $16 / 8 \mathrm{~h}$. Hoagland nutrient solution was applied for seedling growth. The 3-week-old seedlings were moved from the seedling box to provide more sufficient space for further growth until they were ready to be treated at the 4th week of growth.

\section{The geminivirus-derived expression vector and Agrobacterium transformation}

The expression vector based on BeYDV was presented by Professor Mason of Arizona State University. GFP gene was constructed downstream of the $35 \mathrm{~S}$ promoter in the vector as the reporter gene. The expression vector based on BeYDV was transformed into this Agrobacterium LBA4404 strain, and the antibiotic resistance gene of the vector was used for screening and subculture.

\section{Preparation of Agrobacterium cultures}

Agrobacterium tumefaciens LBA4404 strain harboring the BeYDV-derived expression vector with the GFP gene was streaked on Agrobacterium rhizogene medium (YEB) Agar plates containing kanamycin $(50 \mu \mathrm{g} / \mathrm{ml})$, rifampicin $(25 \mu \mathrm{g} / \mathrm{ml})$, and chloramphenicol $(25 \mu \mathrm{g} / \mathrm{ml})$. After $24 \mathrm{~h}$ of growth, the monoclone was picked out from the YEB agar plate and inoculated into $50 \mathrm{~mL}$ YEB broth liquid medium with the antibiotics at $28{ }^{\circ} \mathrm{C}$ overnight in a shaker at $180 \mathrm{rpm}$. The bacteria were collected by centrifugation at $5000 \mathrm{rpm}$ for $10 \mathrm{~min}$ and then washed by infiltration buffer (10 mM MES-KOH, pH 5.5; $10 \mathrm{mM}$ $\mathrm{MgSO} 4 ; 100 \mu \mathrm{M}$ Acetosyringone). After then, the bacteria were collected again and re-suspended in the infiltration buffer. The bacterial concentrations were determined by measuring optical density (OD) at $600 \mathrm{~nm}$ and were diluted to $\mathrm{OD}_{600} 0.3$ with the infiltration buffer.

\section{PGRs treatment and plant transformation}

Three PGRs, NAA, $\mathrm{GA}_{3}$, or 6-BA, with different concentrations $(0.1,0.2,0.4,0.8$, and $1.6 \mathrm{mg} / \mathrm{L}$, respectively), were prepared with distilled deionized water. The seedlings were sprayed three times with different concentrations of NAA, $\mathrm{GA}_{3}$, or 6-BA at 3 days of interval (i.e., for the first spraying, the leaves of 4-week-old seedlings were sprayed with different concentrations of NAA, $\mathrm{GA}_{3}$, or 6 -BA; the second spraying was performed at 3 days after the first spraying, and the third spraying was performed at 3 days after the second spraying). In the control group, the leaves of the seedlings were sprayed with the same amount of distilled deionized water at the under time and under the same conditions. Each spray application was performed until the leaf was wet and the solution ran off. Isolation barriers were set in each spraying to avoid cross-influence.

At 9 days after the first spraying with PGRs, the growth of the sprayed plants was observed, and the parameters of fresh weight, dry weight, and leaf area were measured. At 9 days after the first spraying with PGRs, a small gap was slightly cut in the lower epidermis along the main vein of the leaf, which is $1 / 3$ away from the leaf base and $0.5 \mathrm{~cm}$ away from the main vein. Two mL of Agrobacterium suspension was slowly injected into the leaf through the gap with a sterile syringe without a needle. After infiltration, the plants were moved back to the culture room, and the expression of GFP was monitored at the 4th day after infiltration.

\section{Determination of biomass}

An analytical balance was used to measure the fresh weight of the aerial part of the seedlings. After then, the aerial part of seedlings was put in an oven for deactivation of enzymes at $100{ }^{\circ} \mathrm{C}$ for $20 \mathrm{~min}$, dried to constant weight at $70{ }^{\circ} \mathrm{C}$, and then taken out for weighing the dry weight. For the determination of leaf area, photos of all leaves on each seedling were taken by camera, and Photoshop software was used to measure the leaf area.

\section{Detection of GFP expression}

At the 4th day after the injection of the infiltration buffer, the lower surface of the infiltrated leaf was placed under a Leica fluorescent stereomicroscope (Leica Microsystems Ltd. DFC450 C). A region of $1 \mathrm{~cm}$ away from the original injection site was selected. This region was excited at a wavelength of 450-490 $\mathrm{nm}$ and the emission spectrum between 500 and $550 \mathrm{~nm}$ was recorded.

\section{Data analysis}

The leaf area was measured by Photoshop CS5 software, the GFP fluorescence was analyzed by Image J software, and the data were analyzed by one-way ANOVA with IBM SPSS Statistics 19 software. LSD and Duncan methods were used for multiple comparisons and significance analysis, and the significant difference was expressed by $P$ $<0.05$. The value obtained is the average value of at least 3 independent experiments, and the data are expressed as mean value standard error (SE).

\section{Results}

Effect of NAA on growth and transient expression of Nicotiana benthamiana L. seedlings

In this study, strong GFP expression was observed in the leaves that were infected with LBA4404 carrying 
GFP gene in the BeYDV-derived expression vector, while green fluorescence was not observed in the leaves infected by the Agrobacterium LBA4404 strain without expression vector (Additional file 1: Fig. S1). Thus, the observed green fluorescence was specifically from the expression of the GFP gene.

It can be observed from Fig. 1a that the treatment with $0.1 \mathrm{mg} / \mathrm{L}$ NAA did not significantly affect the biomass of the seedlings, compared to the control (treatment with water). NAA at 0.2 or $0.4 \mathrm{mg} / \mathrm{L}$ significantly increased the fresh weight, dry weight, and leaf area of the seedlings, and the biomass of the seedlings treated with $0.4 \mathrm{mg} / \mathrm{L}$ NAA was significantly higher than that of the seedlings treated with $0.2 \mathrm{mg} / \mathrm{L}$ NAA. However, the $0.8 \mathrm{mg} / \mathrm{L}$ NAA failed to increase the fresh weight, dry weight, and leaf area of the seedlings. When the concentration of NAA reached $1.6 \mathrm{mg} / \mathrm{L}$, the biomass of the seedlings presented a decrease, compared with the control. The fresh weight and dry weight of the seedlings treated with $1.6 \mathrm{mg} / \mathrm{L}$ NAA was decreased significantly by $29.12 \%$ and $23.54 \%$, respectively, while the leaf area was decreased significantly by $18.56 \%$, compared with the control.

The change of the green fluorescence from GFP expression in the infected leaves showed the same trend as that of the biomass of the seedlings (Fig. 1b). Compared with the control, the expression of GFP in the seedlings increased by $3.12 \%, 10.91 \%, 19.00 \%, 0.57 \%$, and $-1.92 \%$ after treatment with $0.1,0.2,0.4,0.8$, and $1.6 \mathrm{mg} / \mathrm{L}$ of NAA, respectively.
Effect of $\mathrm{GA}_{3}$ on growth and the transient expression of the Nicotiana benthamiana L. seedlings

Compared with the control, the treatment with 0.1$0.4 \mathrm{mg} / \mathrm{L} \mathrm{GA}_{3}$ significantly increased the levels of all of the biomass parameters measured (including fresh weight, dry weight, and leaf area) of the seedlings, which peaked at $0.2 \mathrm{mg} / \mathrm{L} \mathrm{GA}_{3}$ (Fig. 2a). However, $0.8 \mathrm{mg} / \mathrm{L} \mathrm{GA}_{3}$ failed to increase the fresh weight and leaf area of the seedlings but increased the dry weight to some extent. When the concentration of $\mathrm{GA}_{3}$ reached $1.6 \mathrm{mg} / \mathrm{L}$, the biomass of the seedlings returned to a level similar to that in the controls.

With the increase of $\mathrm{GA}_{3}$ concentration, the expression of GFP increased at first and then decreased (Fig. 2b). Similar to the effects of $\mathrm{GA}_{3}$ on plant growth, $0.1-0.4 \mathrm{mg} / \mathrm{L} \mathrm{GA}_{3}$ significantly increased the expression of GFP in the seedlings. The enhancement of GFP expression is most obvious when $0.2 \mathrm{mg} / \mathrm{L} \mathrm{GA}_{3}$ was used (increase by $25.28 \%$, compared to the controls). $\mathrm{GA}_{3}$ at other concentration had no significant effects on GFP expression.

\section{Effect of 6-BA on growth and on transient expression of the Nicotiana benthamiana $\mathrm{L}$. seedlings}

Treatment with 6 -BA at 0.2 or $0.4 \mathrm{mg} / \mathrm{L}$ significantly enhanced the levels of all of the biomass parameters measured of the seedlings, and the enhanced effects of $0.2 \mathrm{mg} / \mathrm{L} 6-\mathrm{BA}$ on the growth of seedlings was more obvious than $0.4 \mathrm{mg} / \mathrm{L}$ 6-BA (Fig. 3a). 6-BA at 0.8 and $1.6 \mathrm{mg} / \mathrm{L}$ had no significant effects on the biomass of the seedlings.
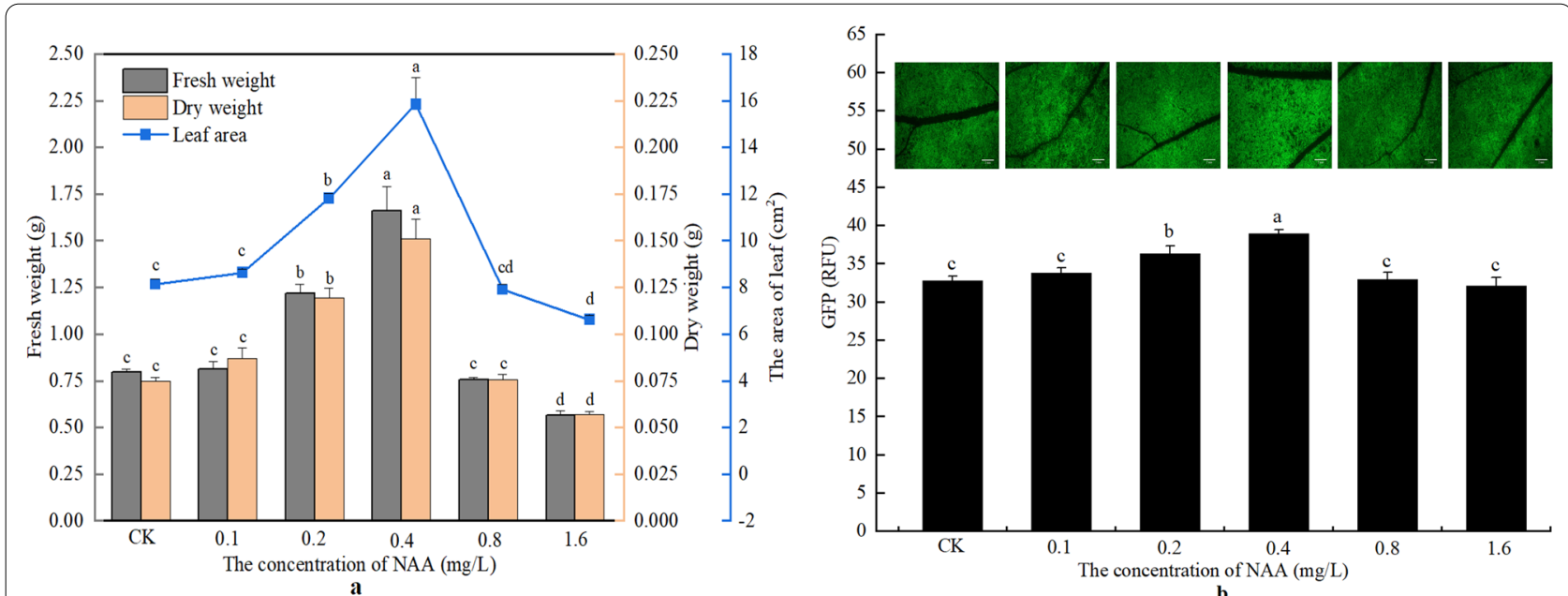

Fig. 1 The changes in biomass and GFP fluorescence intensity of seedlings under different NAA concentrations. a The changes of fresh weight, dry weight, and leaf area of the seedlings after treatment with different concentrations of NAA. $\mathbf{b}$ The changes in GFP fluorescence intensity in the leaves of the seedlings treated with different concentrations of NAA. Bar $=2 \mathrm{~mm}$. CK, Treatment with water; NAA, a-naphthalene acetic acid. The values of RFU (relative fluorescence unit) are average \pm standard error (SE) of three individual replicates. Different lowercase letters indicate that there are significant differences in the same parameter among the treatment with different concentrations of NAA at the $P<0.05$ level 

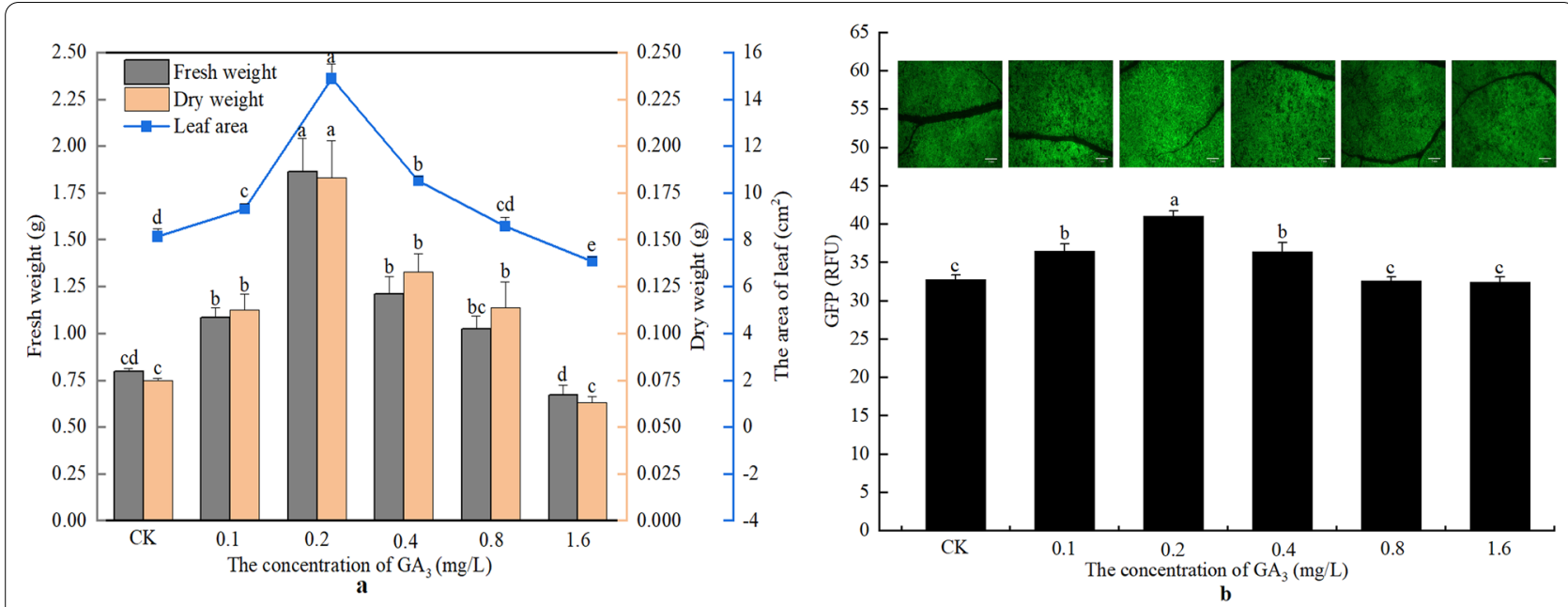

Fig. 2 The changes in biomass and GFP fluorescence intensity of seedlings under different GA ${ }_{3}$ concentrations. a The changes of fresh weight, dry weight, and leaf area of the seedlings after treatment with different concentrations of $\mathrm{GA}_{3}$. $\mathbf{b}$ The changes in GFP fluorescence intensity in the leaves of the seedlings treated with different concentrations of $\mathrm{GA}_{3}$. Bar $=2 \mathrm{~mm}$. CK, Treatment with water; $\mathrm{GA}_{3}$ : gibberellins 3 . The values of RFU (relative fluorescence unit) are average \pm standard error (SE) of three individual replicates. Different lowercase letters indicate that there are significant differences in the same parameter among the treatment with different concentrations of GA3 at the $P<0.05$ level
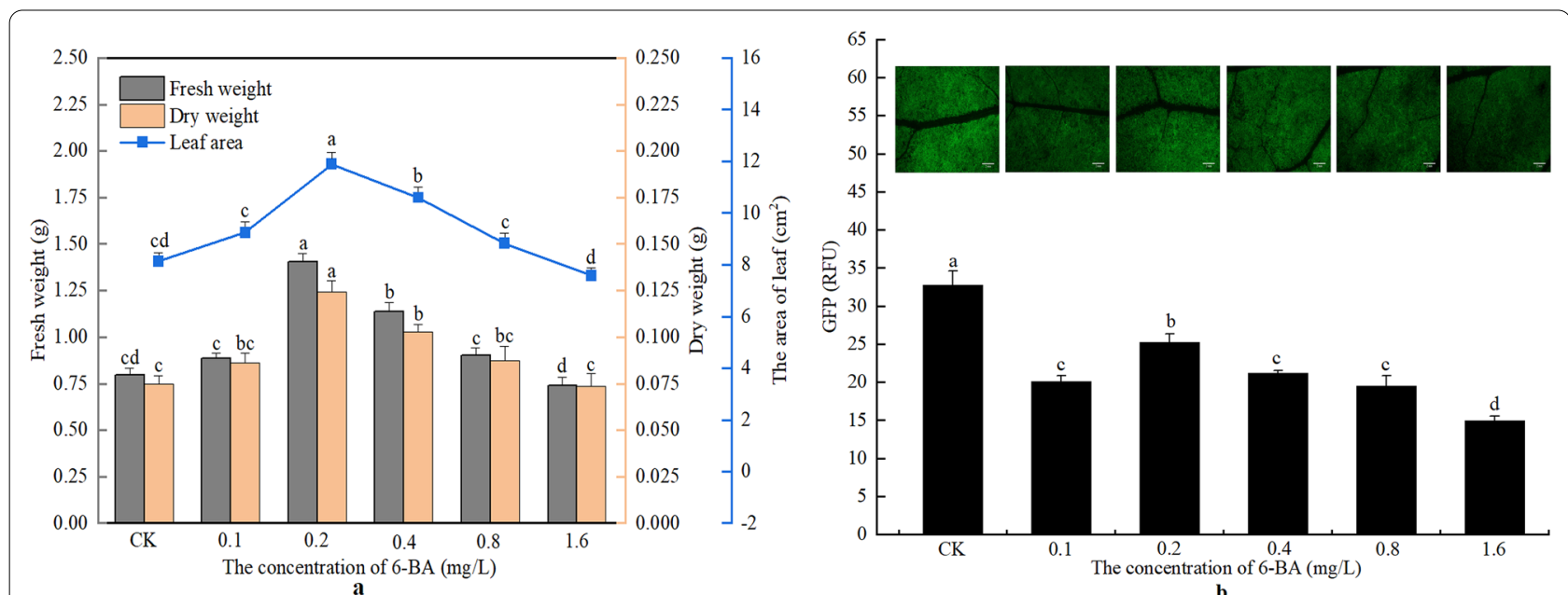

Fig. 3 The changes in biomass and GFP fluorescence intensity of seedlings under different 6-BA concentrations. a The changes of fresh weight, dry weight, and leaf area of the seedlings after treatment with different concentrations of 6-BA. $\mathbf{b}$ The changes in GFP fluorescence intensity in the leaves of the seedlings treated with different concentrations of 6-BA. Bar $=2 \mathrm{~mm}$. CK, Treatment with water; 6-BA: 6-benzyladenine. The values of RFU (relative fluorescence unit) are average \pm standard error (SE) of three individual replicates. Different lowercase letters indicate that there are significant differences in the same parameter among the treatment with different concentrations of 6-BA at the $P<0.05$ level

Treatment with 6-BA decreased the expression of GFP in the leaves (Fig. 3b). Compared with the control, the expression of GFP decreased by $36.68 \%$, $22.75 \%, 35.28 \%, 40.39 \%$, and $54.30 \%$, respectively, after treatment with $0.1,0.2,0.4,0.8$, and $1.6 \mathrm{mg} / \mathrm{L} 6-\mathrm{BA}$, respectively.

\section{Discussion}

It was not surprising that $\mathrm{NAA}, \mathrm{GA}_{3}$, and $6-\mathrm{BA}$ at moderate concentration enhanced the plant growth (Figs. 1a; 2a; 3a). In detail, for the enhancement of the growth, the most effective concentration of these three PGRs is different. NAA at $0.4 \mathrm{mg} / \mathrm{L}$ led to the most 
obvious increase in the biomass of the seedlings, while $\mathrm{GA}_{3}$ and $6-\mathrm{BA}$ at $0.2 \mathrm{mg} / \mathrm{L}$ led to the most obvious increase in the biomass. The discrepancy may originate from the difference in the regulation mechanism of plant growth by these three PGRs. And, our observations are consistent with the previous findings that the effects of auxin, gibberellins, and cytokinin on plant growth are depend on the concentration, with high and low doses eliciting different responses by different mechanisms (Teale et al. 2006; Schaller et al. 2014; Muniandi et al. 2018). For example, below the threshold level, auxin can promote cell division and cell elongation (Wang and Ruan 2013). However, above the threshold level, auxin inhibits cell division and cell elongation. A well-known model of the auxin-stimulated cell expansion is based on the "acid growth theory" (Wang and Ruan 2013). But, the inhibition of cell expansion by high concentration of auxin is attributed to the increase of number of functionally active ARF (auxin response factor) and the transcriptional activation of auxin regulons, rather than the "acid growth theory" (Teale et al. 2006). Thus, the dose-response curve for the growth of plant cells over the increased concentration of exogenous auxins commonly shows the bell-shaped curve (Campanoni and Nick 2005), which was also presented by out observation. In conclusion, a moderate concentration of PGRs for plant growth is needed.

The aim of this study is to evaluate the effects of NAA, $\mathrm{GA}_{3}$, and 6-BA on the efficiency of transient expression. The results showed that NAA and $\mathrm{GA}_{3}$ at moderate concentration can enhance the level of transient expression. Among the concentrations of NAA used, $0.4 \mathrm{mg} / \mathrm{L}$ NAA led to the largest enhancement of transient expression of GFP (transient expression of GFP was enhanced by 19\%). For $\mathrm{GA}_{3}$, the largest enhancement of transient expression of GFP was achieved by $0.2 \mathrm{mg} / \mathrm{L} \mathrm{GA}_{3}$ (transient expression of GFP was enhanced by $25 \%$ ). And, it seems that there was a certain correlation between the transient expression efficiency and growth among the seedlings treated with either NAA or $\mathrm{GA}_{3}$ (from Additional file 1: Fig. S2). This raises a possibility that the effect of NAA or $\mathrm{GA}_{3}$ on transient expression efficiency of Nicotiana benthamiana $\mathrm{L}$. seedlings could be related to the growth of plants. In fact, auxin and gibberellin are known to promote plant growth by inducing cell wall relaxation (Sánchez-Rodríguez et al. 2010). Although loosening the cell wall is a vital process during growth and development, it may also render the plant more vulnerable to biotic intruders by facilitating pathogen entry, allowing enhanced nutrient leakage, and increasing availability of resources for pathogens (Depuydt et al. 2009). Thus, pathogens might benefit from the auxin- or gibberellininduced enhancement of growth of host. Combining these findings with our observations, we assume that the promoted growth of plants by the moderate concentrations of IAA and $\mathrm{GA}_{3}$ is benefit to Agrobacterium tumefaciens for their infection and spread. As a result, the transient expression efficiency was increased. With the further increase of concentrations of IAA and $\mathrm{GA}_{3}$, the enhanced effect of IAA and $\mathrm{GA}_{3}$ on host growth became weaken (or the inhibitory effect of IAA and $\mathrm{GA}_{3}$ on host growth increased). This decreased the utilization of host cells by Agrobacterium tumefaciens for their infection and spread. This could explain why IAA and $\mathrm{GA}_{3}$ did not affect the transient expression efficiency by a dosedependent manner, and the highest concentrations of IAA and $\mathrm{GA}_{3}$ did not effectively enhance the transient expression efficiency.

Different from the effects of IAA and $\mathrm{GA}_{3}$ on the transient expression efficiency, the treatment with 6-BA treatment decreased the level of transient expression of GFP, although it can enhance plant growth at a moderate concentration $(0.2-0.4 \mathrm{mg} / \mathrm{L})$. It was found that exogenous application of high concentrations $(10-100 \mu \mathrm{m})$ of 6-BA to Arabidopsis seedlings before pathogen inoculation can decrease the susceptibility of the seedlings to the biotrophic oomycete Hyaloperonospora arabidopsidis (Argueso et al. 2012; Albrecht and Argueso 2017). And, some works also showed that cytokinin can induce the resistance of plants to pathogen by salicylic acid-dependent signaling pathway (Albrecht and Argueso 2017). These evidences indicate that 6-BA can actually increase the resistance of the plant to pathogen by directly stimulating host defense. Thus, it is reasonable to assume that 6-BA application could trigger the defense of Nicotiana benthamiana L. seedlings to Agrobacterium tumefaciens, thus reducing the transient expression efficiency. Such effect could also overcome the positive effects of 6-BA on Agrobacterium tumefaciens infection and spread when 6-BA at moderate concentration enhances the growth of host plant.

It should be also noted that the Agrobacterium-mediated transient expression is a complex process involving a series of biological events, including Agrobacterium tumefaciens infection, T-DNA transfer from Agrobacterium tumefaciens, protein biosynthesis, and its accumulation in leaf tissue (Gelvin 2003; Jamal et al. 2009; Matsuda et al. 2018). At the same time, the effects of PGRs on plants are also very complex. Thus, more works are needed to obtain clear mechanism for the effects of different PGRs on the level of transient expression.

Regardless of how complex the mechanisms for the effects of these PGRs on the transient expression, the aim of the present work is to present whether the PGRs could be used to enhance the efficiency of Agrobacterium-mediated transient expression systems. 
In the current works about improving the efficiency of transient gene expression in plants, much attention is focused on the optimization of the vector by molecular biological methods. And, some works also made attempts to enhance the efficiency of transient gene expression by modifying external factors, mainly including light, temperature, and humidity (Fujiuchi et al. 2016, 2014, 2017; Matsuda et al. 2017). However, it is difficult or high cost to control temperature, humidity, and illumination when transient gene expression is utilized to produce pharmaceutical-grade recombinant proteins. In comparison, PGRs can be easily applied and cost-efficient if they can be effective to increase recombinant protein yields from transient gene expression in plants. And, there are no security concerns when PGRs are used. As demonstrated by the present work, appropriate PGRs at moderate concentration could be a benefit for the yield of foreign protein and plant growth. Of course, further work is needed to evaluate the effect of PGRs on the production of pharmaceutical protein from Agrobacterium-mediated transient expression system in plants.

In conclusion, appropriate PGRs can enhance the efficiency of transient gene expression. Thus, they have the potential to be considered as the exogenous components to be applied in recombinant protein production by plant-based transient expression systems.

\section{Abbreviations}

BeYDV: Bean yellow dwarf virus; GFP: Green fluorescent protein; NAA: a-Naphthalene acetic acid; GA; : Gibberellins 3 ; 6-BA: 6-Benzyladenine; PGRs: Plant growth regulators; YEB: Agrobacterium rhizogene medium.

\section{Supplementary Information}

The online version contains supplementary material available at https://doi. org/10.1186/s40643-021-00480-5.

Additional file 1: Figure S1. The fluorescent expression of GFP in LBA4404 strains without BeYDV-derived expression vector (left) and with LBA4404 strains containing BeYDV expression vector (right). Bar $=2 \mathrm{~mm}$. Figure S2. The correlation between fresh weight, dry weight, leaf area, and GFP expression of the seedlings under 0.4 and $0.2 \mathrm{mg} / \mathrm{L}$ treatments of NAA (left) and $\mathrm{GA}_{3}$ (right), respectively. The asterisks $\left(^{*}\right)$ indicate that different parameters are significantly correlated at the $P<0.05$ level, and the closer the value is to 1 , the stronger the correlation.

\section{Acknowledgements}

The authors wish to thank the Professor Mason of Arizona state university for the materials.

\section{Authors' contributions}

$Y L$ and MS performed the core experiments and wrote the original manuscript draft. XW and Y-JZ performed the data analysis using Photoshop CS5, Image J, and IBM SPSS Statistics 19. X-WD performed the green fluorescence intensity determination experiments. L-YJ and H-LP provided the resources and supervision. H-QF conceptualized, administered, reviewed, and edited the manuscript. All the authors read and approved the final manuscript.

\section{Funding}

The authors wish to thank the Special Fund for Guiding Scientific and Technological Innovation Development of Gansu Province (Grant Number 2019ZX05), the Open Fund of New Rural Development Institute of Northwest Normal University, the National Natural Science Foundation of China (Grant Number 31870246), and the Key Research and Development Project of Gansu Province (Grant Number 18YF1NA051) for funding this work.

\section{Availability of data and materials}

The data generated and/or analyzed during this study are available from the corresponding author on reasonable request.

\section{Declarations}

Ethics approval and consent to participate

Not applicable.

\section{Consent for publication}

The authors approved the consent for publishing the manuscript.

\section{Competing interests}

The authors declare that they have no competing interests.

Received: 7 September 2021 Accepted: 4 December 2021

Published online: 14 December 2021

\section{References}

Abrahamian P, Hammond RW, Hammond I (2020) Plant virus-derived vectors: applications in agricultural and medical biotechnology. Annu Rev Virol 7(1):513-535. https://doi.org/10.1146/annurev-virology-010720-054958

Albrecht T, Argueso CT (2017) Should I fight or should I grow now? The role of cytokinins in plant growth and immunity and in the growth-defence trade-off. Ann Bot 119(5):725-735. https://doi.org/10.1093/aob/mcw211

Argueso CT, Ferreira FJ, EppleP TJP, Hutchison CE, Schaller GE, Dangl JL, Kieber JJ (2012) Two-component elements mediate interactions between cytokinin and salicylic acid in plant immunity. PLoS Genet 8(1):e1002448. https://doi.org/10.1371/journal.pgen.1002448

Baltes NJ, Gil-Humanes J, Cermak T, Atkins PA, Voytas DF (2014) DNA replicons for plant genome engineering. Plant Cell 26(1):151-163. https://doi.org/ 10.1105/tpc.113.119792

Campanoni P, Nick P (2005) Auxin-dependent cell division and cell elongation. 1-Naphthaleneacetic acid and 2,4-dichlorophenoxyacetic acid activate different pathways. Plant Physiol 137(3):939-948. https://doi.org/10.1104/ pp.104.053843

Chen Q (2008) Expression and purification of pharmaceutical proteins in plants. Biol Eng Trans 1(4):291-321

Chen Q, He J, Phoolcharoen W, Mason HS (2011) Geminiviral vectors based on bean yellow dwarf virus for production of vaccine antigens and monoclonal antibodies in plants. Hum Vaccin 7(3):331-338. https://doi.org/10. 4161/hv.7.3.14262

Chen Q, Lai H, HurtadoJ SJ, Leuzinger K, Dent M (2013) Agroinfiltration as an effective and scalable strategy of gene delivery for production of pharmaceutical proteins. Adv Tech Biol Med 1(1):103. https://doi.org/10. 4172/atbm. 1000103

Damaj MB, Jifon JL, Woodard SL, Vargas-Bautista C, Barros G, Molina J, White SG, Damaj BB, Nikolov ZL, Mandadi KK (2020) Unprecedented enhancement of recombinant protein production in sugarcane culms using a combinatorial promoter stacking system. Sci Rep 10(1):13713. https://doi. org/10.1038/s41598-020-70530-z

Depuydt S, Trenkamp S, Fernie AR, Elftieh S, Renou JP, Vuylsteke M, Holsters $M$, Vereecke D (2009) An integrated genomics approach to define niche establishment by Rhodococcus fascians. Plant Physiol 149(3):1366-1386. https://doi.org/10.1104/pp.108.131805

Fujiuchi N, Matsuda R, Matoba N, Fujiwara K (2014) Effect of nitrate concentration in nutrient solution on hemagglutinin content of Nicotiana benthamiana leaves in a viral vector-mediated transient gene expression system. Plant Biotechnol 31(3):207-211 
Fujiuchi N, Matoba N, Matsuda R (2016) Environment control to improve recombinant protein yields in plants based on Agrobacterium-mediated transient gene expression. Front Bioeng Biotechnol 4:23. https://doi.org/ 10.3389/fbioe.2016.00023

Fujiuchi N, Matsuda R, Matoba N, Fujiwara K (2017) Effects of plant density on recombinant hemagglutinin yields in an Agrobacterium-mediated transient gene expression system using Nicotiana benthamiana plants. Biotechnol Bioeng 114(8):1762-1770. https://doi.org/10.1002/bit.26303

Gelvin SB (2003) Agrobacterium-mediated plant transformation: the biology behind the "gene-jockeying" tool. Microbiol Mol Biol Rev 67(1):16-37. https://doi.org/10.1128/MMBR.67.1.1637.2003

Gong LS, Qu SJ, Huang GM, Guo YL, Zhang MC, Li ZH, Duan LS (2021) Improving maize grain yield by formulating plant growth regulator strategies in North China. J Integr Agric 20(2):622-632

Guan W, Xu P, Wang K, Song Y, Zhang H (2011) Determination and study on dissipation of 1-naphthylacetic acid in garlic and soil using high performance liquid chromatography-tandem mass spectrometry. Food Chem Toxicol 49(11):2869-2874. https://doi.org/10.1016/j.fct.2011.08.009

Hanley-Bowdoin L, Bejarano ER, Robertson D, Mansoor S (2013) Geminiviruses: masters at redirecting and reprogramming plant processes. Nat Rev Microbiol 11(11):777-788. https://doi.org/10.1038/nrmicro3117

Hedden P, Sponsel V (2015) A century of gibberellin research. J Plant Growth Regul 34(4):740-760. https://doi.org/10.1007/s00344-015-9546-1

Hefferon KL (2014) DNA virus vectors for vaccine production in plants: spotlight on geminiviruses. Vaccines 2(3):642-653. https://doi.org/10.3390/ vaccines 2030642

Hwang I, Sheen J, Müller B (2012) Cytokinin signaling networks. Annu Rev Plant Biol 63:353-380. https://doi.org/10.1146/annurev-arpla nt-042811-105503

Jamal A, Ko K, Kim HS, Choo YK, Joung H, Ko K (2009) Role of genetic factors and environmental conditions in recombinant protein production for molecular farming. Biotechnol Adv 27(6):914-923. https://doi.org/10. 1016/j.biotechadv.2009.07.004

Leuzinger K, Dent M, Hurtado J, Stahnke J, Lai H, Zhou X, Chen Q (2013) Efficient agroinfiltration of plants for high-level transient expression of recombinant proteins. J Vis Exp 77:50521. https://doi.org/10.3791/50521

Maleki SS, Mohammadi K, Ji K (2018) Influencing factors of genetic transformation efficiency in tobacco (Nicotiana tabacum 'NC89') using Agrobacterium tumefacience. J Nanjing For Univ 42(1):27-34

Matsuda R, Abe T, Fujiuchi N, Matoba N, Fujiwara K (2017) Effect of temperature post viral vector inoculation on the amount of hemagglutinin transiently expressed in Nicotiana benthamiana leaves. J Biosci Bioeng 124(3):346-350. https://doi.org/10.1016/j.jbiosc.2017.04.007

Matsuda R, Kushibiki T, Fujiuchi N, Fujiwara K (2018) Agroinfiltration of leaves for deconstructed viral vector-based transient gene expression: infiltrated leaf area affects recombinant hemagglutinin yield. Hortic Environ Biotechnol 59(4):547-555

Muniandi SKM, Hossain MA, Abdullah MP, Ab Shukor NA (2018) Gibberellic acid (GA3) affects growth and development of some selected kenaf (Hibiscus cannabinus L.) cultivars. Ind Crops Prod 118:180-187

Peyret H, Lomonossoff GP (2015) When plant virology met Agrobacterium: the rise of the deconstructed clones. Plant Biotechnol J 13(8):1121-1135. https://doi.org/10.1111/pbi.12412

Reed J, Osbourn A (2018) Engineering terpenoid production through transient expression in Nicotiana benthamiana. Plant Cell Rep 37(10):1431-1441. https://doi.org/10.1007/s00299-018-2296-3

Richter KS, Serra H, White $\mathrm{Cl}$, Jeske H (2016) The recombination mediator RAD51D promotes geminiviral infection. Virology 493:113-127. https:// doi.org/10.1016/j.virol.2016.03.014

Rybicki EP, Martin DP (2014) Virus-derived ssDNA vectors for the expression of foreign proteins in plants. Curr Top Microbiol Immunol 375:19-45. https://doi.org/10.1007/82_2011_185

Sánchez-Rodríguez C, Rubio-Somoza I, Sibout R, Persson S (2010) Phytohormones and the cell wall in Arabidopsis during seedling growth. Trends Plant Sci 15(5):291-301. https://doi.org/10.1016/j.tplants.2010.03.002

Schaller GE, Street IH, Kieber JJ (2014) Cytokinin and the cell cycle. Curr Opin Plant Biol 21:7-15. https://doi.org/10.1016/j.pbi.2014.05.015

Teale WD, Paponov IA, Palme K (2006) Auxin in action: signalling, transport and the control of plant growth and development. Nat Rev Mol Cell Biol 7(11):847-859. https://doi.org/10.1038/nrm2020
To JP, Kieber JJ (2008) Cytokinin signaling: two-components and more. Trends Plant Sci 13(2):85-92. https://doi.org/10.1016/j.tplants.2007.11.005

Wang L, Ruan YL (2013) Regulation of cell division and expansion by sugar and auxin signaling. Front Plant Sci 4:163. https://doi.org/10.3389/fpls.2013. 00163

Werner T, Nehnevajova E, Köllmer I, Novák O, Strnad M, Krämer U, Schmülling $T$ (2010) Root-specific reduction of cytokinin causes enhanced root growth, drought tolerance, and leaf mineral enrichment in Arabidopsis and tobacco. Plant Cell 22(12):3905-3920. https://doi.org/10.1105/tpc. 109.072694

Xia P, Hu W, Liang T, Yang D, Liang Z (2020) An attempt to establish an Agrobacterium-mediated transient expression system in medicinal plants. Protoplasma 257(6):1497-1505. https://doi.org/10.1007/s00709-020-01524-x

Zaidi SS, Mansoor S (2017) Viral vectors for plant genome engineering. Front Plant Sci 8:539. https://doi.org/10.3389/fpls.2017.00539

Zhang X, Mason H (2006) Bean Yellow Dwarf Virus replicons for high-level transgene expression in transgenic plants and cell cultures. Biotechnol Bioeng 93(2):271-279. https://doi.org/10.1002/bit.20695

\section{Publisher's Note}

Springer Nature remains neutral with regard to jurisdictional claims in published maps and institutional affiliations.

\section{Submit your manuscript to a SpringerOpen ${ }^{\circ}$ journal and benefit from:}

- Convenient online submission

- Rigorous peer review

- Open access: articles freely available online

- High visibility within the field

Retaining the copyright to your article

Submit your next manuscript at $\boldsymbol{\nabla}$ springeropen.com 